\title{
Healthcare Service on Wheels for Unreached Communities
}

\author{
Takuzo Osugi, Jecinta Kamau, Andrew Rebeiro-Hargrave, Abdullah Emran, and Ashir Ahmed
}

\begin{abstract}
This article introduces an ICT based transport system called Social Services on Wheels (SSW) that provides multiple social services especially healthcare delivery to the unreached communities. A community car brings healthcare devices, PC and team members (Village entrepreneur, healthcare worker, IT assistant) to pre-allocated service points within villages. The measuring devices and applications are supported by a back-end data operations office using Internet. The villager walks to the nearest service point and interfaces with the healthcare and information systems. Social Service on Wheels has been tested in two rural villages in Bangladesh during October 2013 to February 2014. The results showed that 4,496 long distance trips were reduced because the villagers were satisfactorily served without leaving theirvillage. The villagers tended to associate the delivery of six social services with the Toyota community car rather than the SSW teams who performed the tests or helped with IT issues. SSW empowered the community by hiring locally and training the SSW teams. The sustainability of SSW project is a challenging area and is still being investigated.
\end{abstract}

Index Terms-Mobility, access to social service, resource sharing, village centered transportation.

\section{INTRODUCTION}

1 billion of the world population are unreached in terms of access to quality healthcare services [1]. Globally, approximately one half of the population lives in rural areas, but less than $38 \%$ of the nurses and less than $25 \%$ of the physicians work there [2]. On the other hand, prevalence of non-communicable diseases (NCDs), such as heart disease, stroke, cancer, chronic kidney diseases, and diabetes mellitus, has been increasing rapidly worldwide. The World Health Organization reported that NCDs accounted for 63\% (36 million) of the 57 million global deaths in 2008 and approximately $80 \%$ of all NCD-related deaths occurred in low- and middle-income countries [3]. In these developing countries, $29 \%$ of NCD-related deaths occurred in the working-age group (in people aged $<60$ years). This rate is

Manuscript received January 30, 2015; revised April 28, 2015. This work was supported in part by Toyota Motor Corporation, KDDI Foundation Grant Program, Kyushu University $\mathrm{P} \& \mathrm{P}$ program and Grameen Communications.

Takuzo Osugi is with Institute for Academic Initiatives 1st Division, Osaka University, Osaka, Japan and Grameen Communications Specialist Researcher, Bangladesh (e-mail: thosugi@cbi.osaka-u.ac.jp)

Jecinta Kamau is with the Department of Advanced Information Technology, Kyushu University, Fukuoka, Japan.

Andrew Rebeiro-Hargrave is with Institute of Decision Science for a Sustainable Society, Kyushu University, Fukuoka, Japan.

Abdullah Emran is with Grameen Communications, Bangladesh.

Ashir Ahmed is with the Department of Advanced Information Technology, Kyushu University, Fukuoka, Japan. He is also with Grameen Communications, Bangladesh. higher than that for high-income countries (13\%) and contributes to declining labor productivity in developing countries. The total number of annual NCD-related deaths is estimated to reach 55 million by 2030 [4]. NCDs are no longer just a problem for high-income countries, but a problem that affects all countries.

Furthermore, utilization of healthcare services in rural areas is much lower as compared to urban areas. While there are a number of possible explanations for these differences, such as differences in the number of medical practitioners available, the longer travel distances and fewer transportation options available in rural areas are significant factors [5]. The environment of rural communities in developing countries is characterized by an absence of public transport, poor access to welfare services and informal trade markets [6]. In addition, there are few local sustainable business models because independently health, technology and finance are complex and expensive industries [7].

Transport is provided by small-scale private entrepreneurs who run adhoc services without schedule and use substandard vehicles. Welfare services such as healthcare and education are provided at the village level but often at such low quality that villages need to travel outside the community to meet their needs. It hence becomes necessary for people in such rural communities to travel outside the village to access welfare (local clinic or college) and purchase variety (goods not available) villagers use multiple transit services with a repeat cost in price and time.

A solution to the rural public transport deficit is to introduce an affordable scheduled base bus service or taxi minibus [8] that meets the needs of the villages. However, this is not feasible in most cases because the costs of running and maintaining the bus service is greater the revenue gained from low-income clients. Another option is to ask village leaders to collectively invest in a community car(s) and provide a transit service for the local villages [9], [10]. This approach is also not practical because inevitably there will be local disagreements of who would use the community car and for what purpose.

An alternative approach is to focus on the causes of villager mobility [11] and reduce the frequency of transit. The villagers' need for transit is assumed to be based on a negative linear relationship between trip-frequency against distance-travelled. Also, there is high frequency of short distances trips and low frequency of long distance trips. Accepting this, a village community car can influence the trip-distance relationship by reducing the need for villagers to travel.

The villager's primary need for medium to long distance trips are for welfare - health and education and shopping for 
goods not locally available [12]. It is therefore appropriate to reduce the need for medium to long distance travel as these trips are expensive for the villager in terms of financial cost and time. This is achieved by the community car bringing welfare services to villager and using ICT to stabilize the quality.

A healthcare study in rural Bangladesh, a developing country, estimated that if patients were to travel $40-200 \mathrm{~km}$ away to access basic healthcare services, they would spend at least 40 times more money than if the services were readily accessible to them [13].

Social Services on Wheels (SSW) is a mobility approach that will bring welfare services to unreached communities, reducing their necessity to travel long distances to acquire services including healthcare. The system is based on an IT model in which a transit vehicle is used to improve healthcare and productivity of low-come villagers in unreached communities by providing health, education, learning and purchasing services. These services are characterized with high quality delivery and supported by cloud data processing in the city. The SSW model has been tested in Bangladesh and the latest findings will be discussed in this paper.

\section{Villager Centered APPROACH}

The Social Service on Wheels (SSW) concept was designed by Kyushu University in collaboration with Grameen Communications to bring ICT based services to unreached communities [14]. The concept was derived against a general need for a community to own a car. However, as the car cannot be shared by multiple users, most who do not have a driving license, community leaders agreed that vehicle should bring healthcare and IT services to the villages and ferry female students to and from college. The SSW model was improved when e-health (telehealth) system and more advanced IT support were introduced. A cloud data service with a remote doctor service was set up in the city. Currently, the focus is on the villager quality of experience and business sustainability.

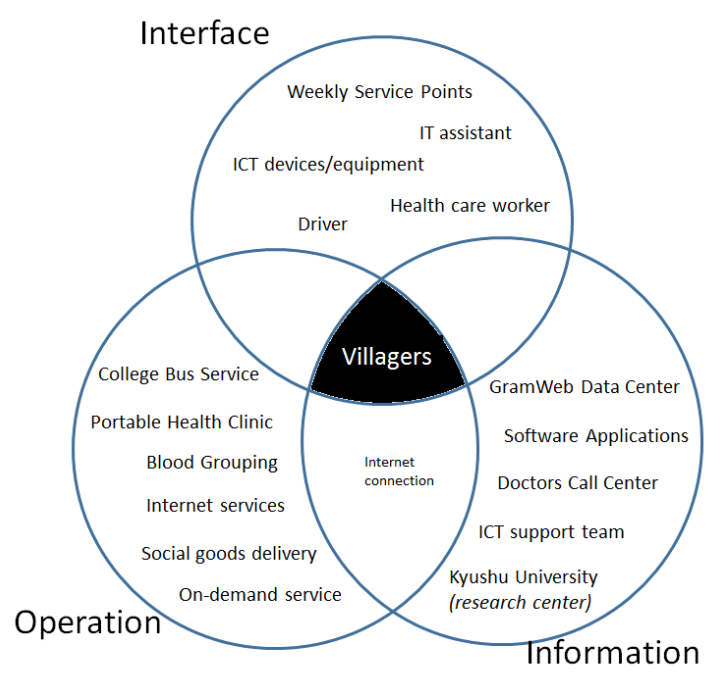

Fig. 1. The Villager is at the intersection of three delivery areas.

The villager centered model is the core component of the
SSW principles. The main principle is to simplify the villager's interaction with the SSW by focusing on three areas: how the village interfaces with the system, the quality of the operation delivered; and what information is gathered and delivered Fig. 1. The villager is a union of these three areas.

\section{A. Social Service on Wheels Operation}

The operation concerns the service logic and how the villager experiences each function. Service logic is affected by time of delivery and number of exchanges between the system and the villager. Each service is described in detail:

Access to education: female students register to the service online. The community vehicle collects the students from pre-determined pick up points and takes them to the college in the morning (between 08:00-09:00). The vehicle then travels to a service point and waits until it is time to collect the students in the afternoon and brings them home.

Access to healthcare: occurs at service points and comprises two services:

Portable Health Clinic (PHC): The PHC is a telehealth application that uses medical devices and sensors to screen villagers for non-communicable diseases such as diabetes and hypertension. The system grades the level of morbidity. Villagers at risk for disease are connected via Sykpe call to a remote doctor who analyzes their electronic health record, provides a diagnosis, and issues a teleprescription [15].

Blood grouping: Villagers are tested and informed of their blood group. The blood group is saved online and forms a virtual blood bank.

Access to learning: villagers can improve their IT skills via an ICT trainer who is part the SSW team. As IT skills are lacking in rural villages, the trainer shows the computer basics to registered participants.

Access to purchasing: covers two areas:

Online purchasing: The villagers can order commodities online and pay the SSW manager. The ordered goods are delivered the following week to the villager. Examples of ordered goods include mosquito nets, locks and sanitary towels.

Online rental of the community car: The villagers can hire the community car whilst it is waiting at the service point or on weekends (Friday and Saturday) through the SSW interface. This is popular for celebrations such as wedding or taking the family to the airport.

\section{B. Social Service on Wheels Information Management}

The remote support of the villager service SSW experience is a fundamental element. The SSW architecture [14] is shown in Fig. 2. The data operation systems comprises of back-end cloud of database, application servers and a doctor call center located in the city. Service delivery to villagers is a front-end activity that occurs at village service points. The back-end and front-end are connected by Internet and 3G mobile network coverage.

The back-end database stores information such as villager registration information, villager electronic health record, client blood group, villager purchase record, and vehicle tracking information. The villager receives a copy of all information, such as the electronic health record after a health 
check-up and receipt after purchasing a service.

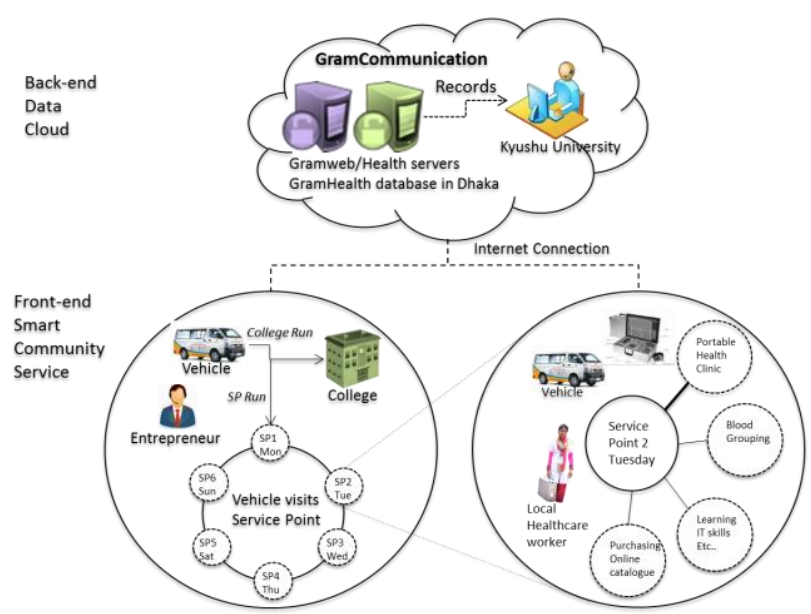

Fig. 2. Services are managed by a remote back-end office.

\section{Flow of Activities}

The villager simultaneously experiences the SSW interface, operations and remote Information Technology support. The flow of activity is shown on Fig. 3. The community vehicle would visit a site pre-advertised to villagers within the community. The vehicle would bring with it a portable health clinic, a computer with internet access and personnel to assist delivering the services; healthcare lady, IT assistant. The villager would visit the site and register for a service with the help of an IT assistant (1). These records would then be uploaded to the remote server in the city/urban area where resources are not as scarce. Villagers can selected services available including: health checkup, blood grouping, internet access/learning, goods ordering and travel requests (2).

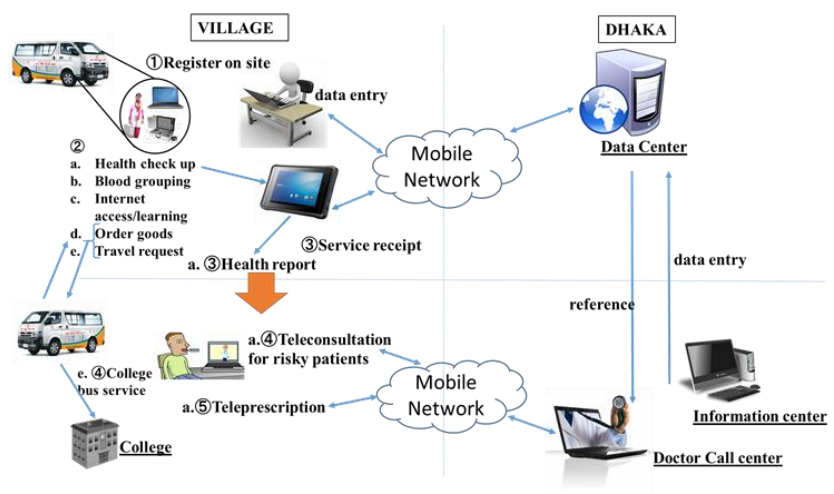

Fig. 3. SSW Flow of activities.

Villagers who select the healthcare service go through a general health checkup or have specific health measurements conducted by the healthcare lady. The checkup details are automatically or manually fed into a triage system that informs the healthcare lady and the patient of their health status. The triage scales the patient's check-up details against pre-known limits and informs the level of the measurements in understandable form; by showing colors red, orange, yellow and green in order of most risky to healthy levels. The healthcare lady prints out the health report and issues it to the patient and explains all details (3)a. If the patient's triage values were red or orange, a teleconsultation session is arranged with doctors on stand-by in the city (4)a. They receive doctor's advice and an e-prescription is sent to the system (5)a. The healthcare lady prints it out and explains the contents to the patient.

Persons who select the blood grouping service have their blood samples taken and within minutes, they are informed of their blood group. The details are printed out and the villager is issued a copy.

For the computer/internet access/learning, the villager get basic training from the IT assistant at a minimal fee. Villagers can also get internet access by connecting to the vehicle onboard wifi connectivity available for free.

Villagers who order goods give the details which are entered to the system and uploaded to the server in the city where the orders are organized for pick up by the vehicle. The soonest time the vehicle picks up the item and visits the site again, the villager receives the ordered items without having to travel themselves.

Travel requests include college bus service and request for use of vehicle when idle. For college bus service, students are registered and pay a monthly fee for the service. Registered students get priority to board the vehicle. The students show their receipts (3) when they board the vehicle. Unregistered students may also board the vehicle on paying a daily fee if the seats capacity is not maximized by registered students.

Villagers may request to use the vehicles by registering at the site. The system checks for availability and informs the villager and gives a quote for the service. They can then get to use the vehicle with the SSW driver during time reserved. Exceeding time reserved carries a penalty to cover costs of disrupting the schedule.

\section{TESTING}

\section{A. Experiment Environment}

Social Services on Wheels has been tested in rural villages in Bangladesh since 2012 to date. The experiment was devised with the objective to evaluate the impact of the multiple services on villages and the sustainability of the community car concept.

Two Toyota Hiace vehicles were leased on a monthly basis. Two SSW teams were formed (entrepreneur, Field Operation worker, Healthcare worker, IT assistant, driver and female driver). The front-end equipment included Portable Health Clinic (medical devices and equipment) packed inside a brief case, blood testing equipment, and PC Note books with headphones for IT training and online e-commerce. One PC Notebook was used for the telemedicine calls. The back-up support environment included the villager database, service applications, and a doctor call center in Dhaka. The most recent test environment was in two rural villages: Bheramara and Kalihati located in Kushtia and Tangail districts in Bangladesh. This paper reports experiment conducted from April 2014 to January 2015.

\section{B. Reduction in Villager Trips}

The overall project goal was to reduce the villagers need to travel by bringing welfare service to the community. In this phase, SSW achieved this by providing 3, 570 villagers with 
multiple services from two locations: Kalihati and Bheramara (Table I). This means a saving of 3, 570 travel trips for two communities.

TABLE I: VILLAGERS IN KALIHATI AND BHERAMARA

Site

\begin{tabular}{|ll|r|r|r|r|}
\hline & & Frequency & Percent & Valid Percent & $\begin{array}{c}\text { Cumulative } \\
\text { Percent }\end{array}$ \\
\hline Valid & Bheramara & 2619 & 73.4 & 73.4 & 73.4 \\
& Kalihati & 951 & 26.6 & 26.6 & 100.0 \\
& Total & 3570 & 100.0 & 100.0 & \\
\hline
\end{tabular}

The Portable health clinic service was most popular, having screened 1570 patients for lifestyle diseases and 1680 villagers knowing their blood group from the blood group typing service provided Fig. 4. The college bus service and computer and internet services had low demand in this phase; with 86 students and 36 people served respectively. 88 people were saved the efforts to search for a reasonable transportation service through the emergency services open to the villagers as a community car. 103 villagers got to save trips to the city by having items delivered to them at their nearest site point.

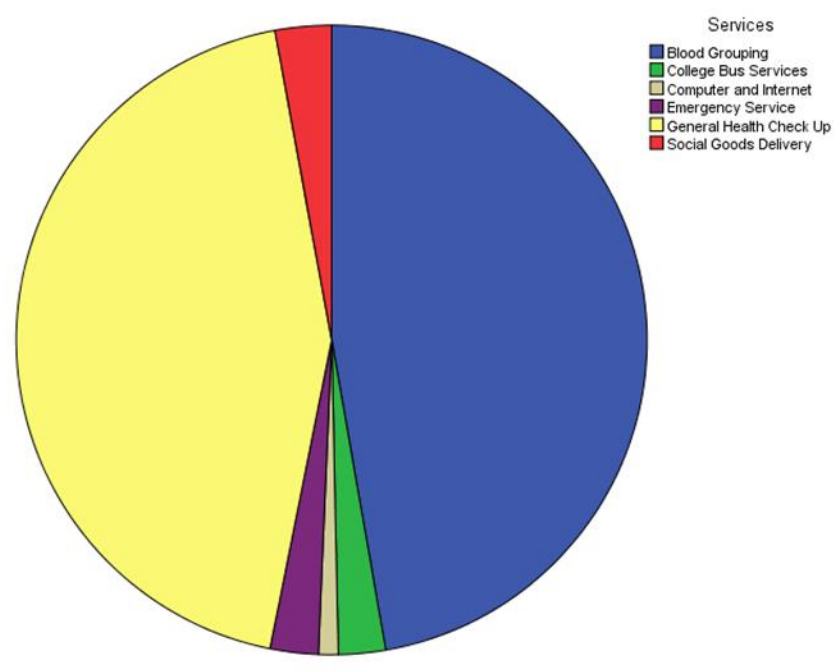

Fig. 4. Distribution of services taken by villagers.

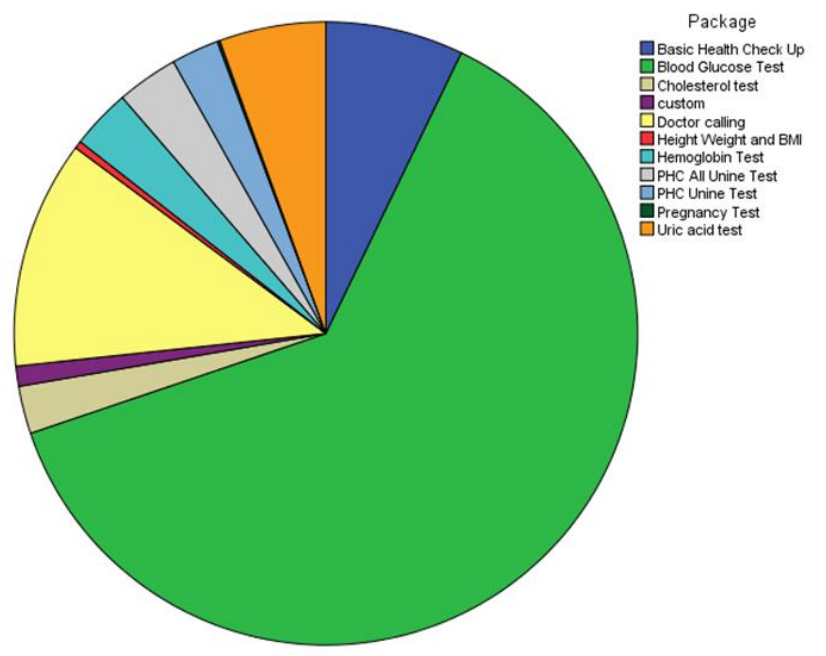

Fig. 5. General health checkup distribution of health check up.

Around $61 \%$ of the General health checkups were blood glucose tests Fig. 5. This means 963 patients received health preventative and maintenance services at a fraction of amount that would have been spent travelling to the city for the same services. $11 \%$ of the Portable Health Clinic patients required doctor's remote connection (telemedicine) services. This can be translated to 182 patients having had their illness prevented from advancing by availing medical care sooner rather than later. Other tests offered included; cholesterol test, hemoglobin test, urine test, pregnancy test and uric acid tests.

\section{Previous Phase}

In the previous phase Portable Health Service had screened 1,965 villages for lifestyle diseases and over $52 \%$ required telemedicine consultation [15]. This is a significant reduction with only $11 \%$ of screened patients requiring telemedicine consultation. Generally, this can be taken to mean that from previous phase, the villagers health status improved considerably, granted there is still more efforts to be undertaken.

Purchasing services maintained the same percentage for both experimental phases. Lessons learned from this is probably researching more on villager consumer trends to market items villagers really need but are not available in the village stores. College bus services ran 693 trips in the previous phase; with the latest phase having served only 86 students. This could be attributed to the frequent change of student schedules that the vehicle wasn't able to match. Real-time scheduling of the vehicle could solve this problem for the students and for the service provision as well.

\section{Villager Perception}

It is important to ascertain the villager's perception of the SSW model. The combination of a transit vehicle with a cross range of fundamental services may be difficult for the villager to comprehend. There is little linkage between a healthcare services for diabetes screening, computer and internet training and social goods purchasing even though there are all provided at the same time. When questioned about their perception of SSW system, villagers tended to associate the perceived benefits with the Toyota vehicle which was branded GramCar (literary Village Car) rather than the SSW team members. This is supported by a comparison study, when the SSW services were brought to the service point by local vehicles against when the SSW services were brought by the GramCar. Although, the villages received the same services their appreciation and evaluation of the SSW was twice a greater when brought by the Toyota vehicle than without Fig. 6. The appreciation of the vehicle itself increased the value of the car for on-demand hiring services where it was considered a luxury vehicle to carry people to weddings and important events.

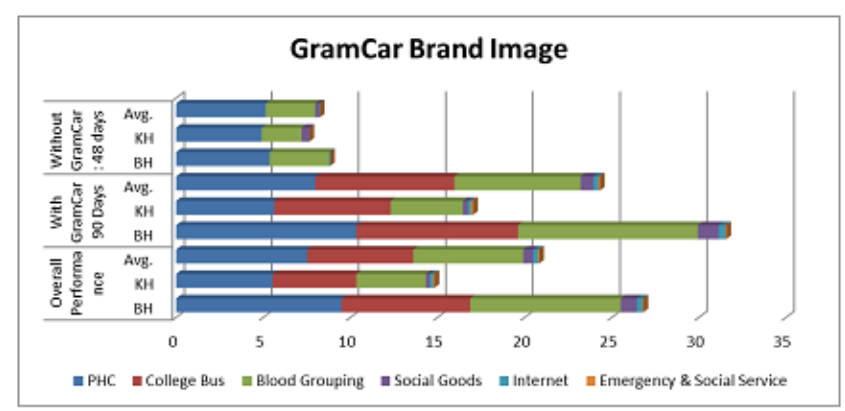

Fig. 6. Villager perception of the vehicle. 


\section{E. SSW Sustainability Methods}

Business sustainability or rather the ability to be replicated in different communities with similar or closely related conditions (developing countries) is the overall success of the SSW model [14]. The SSW system faces the same problems as any business in a rural village: costs of running and maintaining the business is greater than the revenue gained from low-income clients. Much experimental emphasis has been placed on creating a viable SSW business model. The notion of creating multiple services is to increase revenue streams, so that services in demand such as healthcare and vehicle hire can supplement the costs of providing a transit service for female students. In the most recent phase, blood grouping services was offered at a very minimal cost in efforts to encourage villagers from utilizing the other services provided.

The most expensive cost components of the SSW project are the monthly vehicle rental and ICT back-end support, in particular, doctor call center costs. Analyzing the profitability of the project, the field experiment showed that the revenue from all the six services only covered a slight fraction of the total cost. The transit service (emergency service) accounted for the majority of revenue collected at $45 \%$. Social goods and healthcare services gathered $16 \%$ and $22 \%$ respectively. Blood grouping service realized $12 \%$ of the revenue. The rest of the revenue was shared among computer and internet services and the college bus service (see Fig. 7).

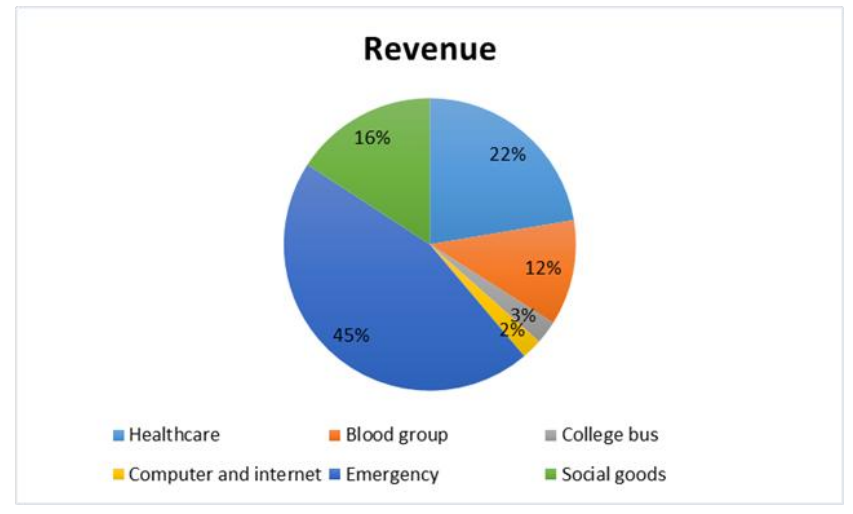

Fig. 7. Revenue of the SSW project.

\section{CONCLUSIONS}

This study introduced an ICT based community car to reduce the village trip-frequency by bringing access to healthcare and welfare directly to the villager. Using the SSW, the villager did not travel outside the village to access e-healthcare, education, e-learning and e-purchasing services This is a villager centered transport approach because mobility comes to the user rather than the villager becoming mobile. The social services are wrapped around the villager and quality of service and quality of experience become important decision-making parameters. The SSW service has been appreciated by villages in two rural sites in Bangladesh. However, there are many limitations: SSW is small scale serving 11 female students and service points are not always busy. The real impact of SSW campaign would not be appreciated unless there were a fleet of community cars providing many opportunities for villagers to interface with the various services. There is no interlinking between services: a diabetic is only interested in getting blood and urine glucose measured [16]. A housewife looking for mosquito net is only interested in ordering and purchasing that item. The business model is not yet stable and currently the SSW cannot run independently without financial support from research parties. Accepting these and other problems Social Service on Wheels is an ambitious project that uses ICT to support a village owned community car.

\section{REFERENCES}

[1] Global Health Issues. (September, 2012). [Online]. Available: http://www.globalissues.org/issue/587/health

[2] Increasing Access to Health Workers in Remote and Rural Areas through Improved Retention, World Health Organization, Global policy recommendations, 2010.

[3] Global Status Report on Noncommunicable Diseases, 2010 World Health Organization, Geneva, 2010.

[4] Non-Communicable Diseases - A Major Health Challenge of the 21st Century. (2012). [Online]. Available: http://www.who.int/gho/publications/world_health_statistics/2012/en

[5] J. Mattson, "Transport, distance and healthcare utilization for older adults," October 2010.

[6] A. Hammond, W. J. Kramer, J. Tran, R. Katz, and C. Walker, "The next 4 billion: Market size and business strategy at the base of the pyramid," World Resources Institute, March 2007.

[7] C. Qiang, M. Yamamichi, V. Hausman, R. Miller, and D. Altman, Mobile Applications for the Health Sector, ICT Sector Unit, World Bank, April 2012.

[8] R. Caarruthers, M. Dick, and A. Saurkar, "Affordability of pulbic transport in developing countries," Transport Papers, TP-3, Washington D.C: The World Bank Group, January 2005.

[9] F. E. Prettenthaler and K. W. Steininger, "From ownership to service use: The potential of car sharing," Ecological Economics, vol. 28, pp. 443-453, 1999.

[10] A. Millard, G. Murray, J. Ter, C. Fox, and J. Burkhardt, "Car sharing Where and how it succeeds," Transit Co-operation Research Program Report 108, Washington, D.C:Transpotation Research Board, 2005.

[11] C. Wilson, "Understanding the dynamics of socio-economic mobility: Tales from two Indian villages," Overseas Development Institute 2004.

[12] F. Stewart, "Basic needs in developing countries," Johns Hopkins Studies in Development, Baltimore: John Hopkins University Press, 1985.

[13] E. Kai and A. Ahmed, "Remote health consultancy service for unreached community: Amazing facts and technical challenges," in Proc. First MJIIT-JUC Joint Symposium, MJIIT, UTM, Kuala Lumpur, Malaysia, Nov. 2012.

[14] J. Kamau, A. Reberio, H. Saito, E. Abdullah, H. Okajima, and A. Ahmed, "Social services on wheels: A sustainable model to improve access in unreached communitites," in IST-Africa Proc. International Information Management Corporation IIMC, 2014

[15] J. Kamau, A. R. Hargrave, E. Abdullah, I. Rafiqul, K. Nobuhara, H. Okajima, and A. Ahmed, "Villager centered transport system in unreached communities," presentd at The 2014 IEEE International Conference on Systems, Man, and Cybernetics (SMC2014), October 5-8, 2014, San Diego, CA, US.

[16] E. Kai and A. Ahmed, "Technical challenges in providing remote health consultancy service for unreached community," presented at $27^{\text {th }}$ IEEE Conference (AINA), FINA-2013 Workshop, Barcelona, Spain, March 2013.

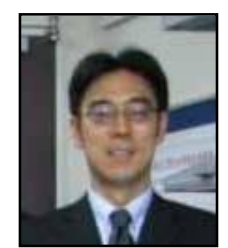

T. Osugi is now an associate professor at Institute for Academic Initiatives, Osaka University. He received his $\mathrm{Ph} . \mathrm{D}$. degree in social and cultural studies from Kyushu University, Fukuoka Japan in 2012. His research interest includes ICT4D (information and communication technologies for development), community informatics and social business. 


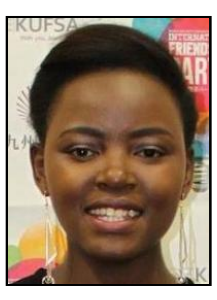

J. W. Kamau is a master's student in Kyushu University and started research activities in Kyushu University in October, 2013. Prior to that, she had graduated from Strathmore University in Kenya (June, 2012) with a bachelor degree in business and information technology majoring in database systems. She then worked as an education systems executive at Technology Partners in Kenya. Before moving to Japan she was an adjunct faculty at St. Paul University, Kenya specializing in database systems and web applications programming. She was granted a MEXT post graduate scholarship to study at Kyushu University. Her research interests included demand responsive transportation, transportation systems for the last mile, technologies for the unreached.

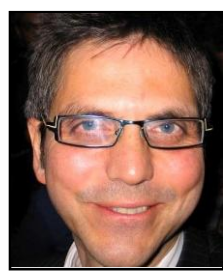

A. Rebeiro-Hargrave is currently a lecturer with Institute of Decision Science for Sustainable Society, Kyushu University. He spent 6 years with Nokia Siemens Networks solution selling in emerging markets (Kenya 2006 -2012) and 6 years with Nokia Networks in research and development (multimedia and IP communication) (Finland 2006-2006) prior to that, he spent 6 years at King's College London writing a Ph.D. thesis on cellular automata modeling and teaching geography (London 1994-2000).

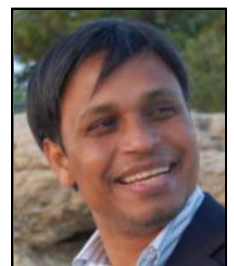

A. Ahmed is an associate professor at the Department of Advanced Information Technology in Kyushu University, Japan and the director of GCC project in Grameen Communications, Bangladesh. After receiving his Ph.D. degree from Tohoku University in 1999, he worked with Avaya Labs and NTT Communications, Japan in R\&D VOIP systems. His current research aims to develop ICT for development in fields including from healthcare, mobility and agriculture. He is a member of IEEE, EMBS and IEICE.

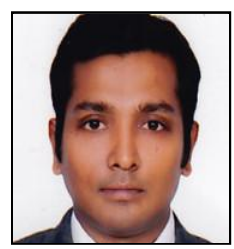

E. Abdullah is a project manager of the SSW project, and a joint research project among Toyota, Kyushu University and Grameen. He received his master degree in e-business management from International University, Japan and MBA in finance from University of Dhaka, Bangladesh. He designs sustainable business models and creates small and medium social entrepreneurs to serve social services in unreached communities. Social business in the areas of mobility, ecommerce, healthcare is his major areas of research 